\title{
A Case of Chronic Myeloid Leukemia Presenting with Osteoid Osteoma: A Diagnostic Dilemma
}

\author{
Mannavi Suman ${ }^{1}$,Anis Bandyopadhyay ${ }^{2}$, Arnab Kumar Ghosh $^{3}$, Sk Rahamatulla ${ }^{3}$, \\ Alakananda Choudhury ${ }^{3}$
}

${ }^{1}$ Department of Medical Oncology, Tata Memorial Hospital, Mumbai, India. ${ }^{2}$ Department of Radiotherapy, Nil Ratan Sarkar Medical College and Hospital, Kolkata, India. ${ }^{3}$ Department of Radiotherapy, Medical College Kolkata, India.

\begin{abstract}
Chronic myeloid leukemia is a hematological malignancy resulting from a clonal proliferation of hematopoietic stem cells of the myeloid series. It is developed by chromosomal translocation. Chronic Myeloid Leukemia (CML) usually occurs in adults and is rare in children. Osteoid osteoma is a benign bone lesion with no malignant potential. The association of chronic myeloid leukemia with osteoid osteoma is not reported in the literature. An atypical presentation of osteoid osteoma may complicate the diagnosis when associated with a primary malignancy. In this report, we have discussed a case of atypical presentation of osteoid osteoma suspected to be a lytic bone lesion in CML.
\end{abstract}

Keywords: Chronic myeloid leukemia- osteoid osteoma- sacrum- atypical osteoid osteoma

Asian Pac J Cancer Care, 6 (3), 353-355

\section{Introduction}

Chronic myeloid leukemia (CML) is a clonal hematopoietic disorder, accounting for $15 \%$ of all leukemia. According to the SEER program, the median age of diagnosis is 66 years, which is much higher than reported in many trials [1]. The disease is usually seen in adults in the age group of 50 to 60 years, with a slight male predominance [2]. The discovery of the Philadelphia chromosome in 1960 made CML the first neoplasm to be characterized by cytogenetic marker [3]. The only risk factor for the development of CML is exposure to high radiation doses and is evident from survivors of the atom bomb explosion in Japan in 1945 and follow-up of patients treated with radiation for ankylosing spondylitis and cervical cancer [4].

Osteoid osteoma is a benign bone tumor diagnosed usually in males in the age group of 5-35 years [5]. It is usually found in the long bones of extremities and presents with long-standing history of pain, typically nocturnal pain, which is relieved by salicylates [6]. Rare location and atypical radiological presentation may delay the diagnosis and treatment [7]. Here we report
Submission Date: 01/21/2021 Acceptance Date: 06/02/2021

\footnotetext{
Corresponding Author:

Dr. Arnab Kumar Ghosh

Junior Resident, Department of Radiotherapy, Medical College Kolkata, India.

Email: arnabkumarghosh27@gmail.com
}

a case of CML that presented with osteoid osteoma at a rare site.

\section{Case Description}

A 54-year-old female patient, a known case of CML with a clinical history of leukocytosis, hepato-splenomegaly, and BCR-ABL positive for the last 8 months was referred to us for evaluation of a two weeks history of back and right gluteal region pain which was aggravated by movement and relieved on lying prone. On examination, there was extreme tenderness over the right side of the sacrum, the straight leg raising test was positive, and hip movement was painful. CT (Computed Tomography) scan suggested a lytic lesion in the right ala of the sacrum. We suspected this to be a bone involvement in CML and started the patient on pain medicines and the first dose of zoledronic acid and sent for further investigation.

PET CT suggested increased metabolic activity in the right sacral ala (Figure 1). Bone scintigraphy reported a fairly well-defined radiolucent area surrounded by sclerotic rim showing increased uptake in right sacral 


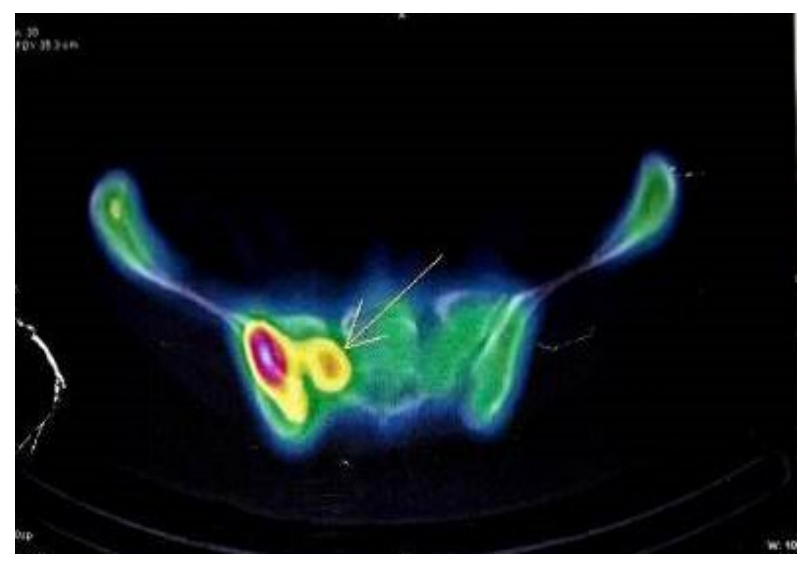

Figure 1. PET- CT Showing Increased Metabolic Activity in Right Sacral Ala

ala at S2 vertebral level, and the lesion was suspected to be an osteoid osteoma (Figure 2). A needle biopsy was done which reported features of woven bone and the presence of osteoblasts and osteoclasts, thus, supporting the findings of bone scintigraphy. After a confirmatory diagnosis of the benign condition, the patient was referred to the department of orthopedics for further treatment.

\section{Discussion}

Chronic myeloid leukemia is a biphasic or triphasic illness. The disease can progress to more aggressive leukemia as a malignant clone loses the capacity for terminal differentiation. BCR-ABL TKI is the standard frontline therapy for newly diagnosed cases of the chronic phase of chronic myeloid leukemia [8]. Allogenic $\mathrm{HCT}$ is reserved for patients with resistance to TKI or management of advanced phase due to its morbidity and mortality. Cases of secondary malignancy are very few in the literature. Secondary primary malignancy of the breast, neuroendocrine tumor of the caecum, squamous cell carcinoma of the skin, acute lymphocytic leukemia have been reported but there has been no case of any benign tumor being reported in the literature [9-11]. Elmhadi et al reported a case of successful management of synchronous recurrent breast carcinoma with chronic myelogenous leukemia [12]. Pan L et al reported a case of secondary breast carcinoma after completely remitted chronic myeloid leukemia following targeted tyrosine kinase therapy [13]. Campione $\mathrm{E}$ et al reported a case of Kaposi sarcoma in a patient treated with imatinib mesylate for chronic myeloid leukemia [14].

Treatment of osteoid osteoma comprised of conservative management to excision and newer techniques like radiofrequency ablation [6]. Osteoid osteoma is a benign condition and its malignant transformation has not been reported in the literature [15]. However, various atypical presentations of the benign tumor may delay diagnosis, especially when associated with a malignant condition [7]. The typical presentation of osteoid osteoma is a long-standing history of pain which is

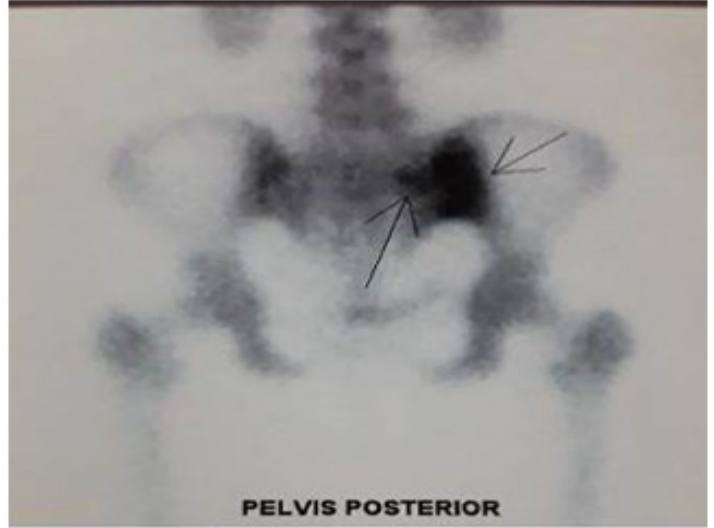

Figure 2. Bone Scintigraphy Image of the Sacral Ala Lesion (marked by black arrows)

relieved by salicylates, male sex, and an age group of 5-35 years. $50 \%$ are located in the long bones of the extremity with the least common locations being skull, pelvis, ribs scapula, etc. [7]. Typical CT scan finding is a central nidus with variable attenuation and surrounding sclerosis [16]. Various atypical features like bone destruction, marrow edema, periosteal reaction, sclerosis obscuring nidus, and complete sclerotic lesion may obscure the diagnosis [7].

Our patient had presented at an age of 54 years, with a short 2 weeks history. CT findings show a right sacral ala lytic lesion. Older age of presentation, sacral location, and lytic lesion on CT are not typical findings of osteoid osteoma-which led to diagnostic delay. Moreover, its association with CML complicated the picture. Various case reports and series in the literature have reported a solitary lytic bone lesion in CML (17-20). These lesions usually precede a blastic phase and suggest a poor prognosis. A lytic lesion in CML is usually treated with hypofractionated radiotherapy for pain and pain medications according to the WHO pain ladder. Thus, an atypical presentation of osteoid osteoma and an association with CML complicated the diagnosis of osteoid osteoma.

There is one case report in the literature that reported an intracortical bone metastasis presenting with features of intracortical osteoid osteoma in a patient with lung adenocarcinoma [21]. Thus, a bone lesion in a patient with a primary malignancy should call for an extensive investigation to rule out metastatic or malignant disease.

A CML co-presenting with osteoid osteoma has not been reported in the literature. Our case is unique because the presentation was at a rare site with atypical CT features complicating the diagnosis. We may also conclude that a tissue diagnosis should always be carried out in a bone lesion with an associated primary malignancy.

In conclusion, chronic myeloid leukemia is a hematological malignancy and its presentation with osteoid osteoma has not been seen in the literature. An atypical presentation of the benign bone lesion may complicate the diagnosis and should be confirmed by histopathology. 
Ethics Approval, Statement of Compliance, and Clinical Trial Transparency

Ethical committee approval was taken for the publication of this document. Informed consent of the patient was taken for the publication of clinical findings.

\section{Abbreviations}

CML- Chronic Myeloid Leukemia, CT- Computed Tomography

\section{References}

1. Rohrbacher M, Hasford J. Epidemiology of chronic myeloid leukaemia (CML). Best Practice \& Research Clinical Haematology. 2009 09;22(3):295-302. https://doi. org/10.1016/j.beha.2009.07.007

2. Singhal MK, Sengar M, Nair R. Summary of the published Indian data on chronic myeloid leukemia. South Asian Journal of Cancer. 2016 07;05(03):162-165. https://doi. org/10.4103/2278-330x.187593

3. Nowell C. The minute chromosome $(\mathrm{Ph} 1)$ in chronic granulocytic leukemia. Blut Zeitschrift für die Gesamte Blutforschung. 1962 04;8(2):65-66. https://doi.org/10.1007/ bf01630378

4. Brown WM, Doll R. Mortality from cancer and other causes after radiotherapy for ankylosing spondylitis.. BMJ. 1965 Dec 04;2(5474):1327-1332. https://doi.org/10.1136/ bmj.2.5474.1327

5. Boscainos PJ, Cousins GR, Kulshreshtha R, Oliver TB, Papagelopoulos PJ. Osteoid Osteoma. Orthopedics. 2013 Oct;36(10):792-800. https://doi.org/10.3928/0147744720130920-10

6. Noordin S, Allana S, Hilal K, Nadeem N, Lakdawala R, Sadruddin A, Uddin N. Osteoid osteoma: Contemporary management. Orthopedic Reviews. 201809 25;10(3). https://doi.org/10.4081/or.2018.7496

7. Carneiro BC, Da Cruz IAN, Ormond Filho AG, Silva IP, Guimarães JB, Silva FD, Nico MAC, Stump XMGRG. Osteoid osteoma: the great mimicker. Insights into Imaging. 202103 08;12(1). https://doi.org/10.1186/s13244-02100978-8

8. Goldman JM. How I treat chronic myeloid leukemia in the imatinib era. Blood. 2007 Oct 15;110(8):2828-2837. https:// doi.org/10.1182/blood-2007-04-038943

9. Eskazan A, Caliskan T. Second primary malignancies in chronic myeloid leukemia patients. Journal of Cancer Research and Therapeutics. 2015;11(4):1042. https://doi. org/10.4103/0973-1482.154928

10. Novaković S, Kovač Peić A, Holik H, Coha B. Neuroendocrine tumor of cecum in patient treated with imatinib mesylate for blastic phase of chronic myeloid leukemia. Acta Clinica Belgica. 201704 19;72(6):461-464. https://doi.org/10.1080 /17843286.2017.1316005

11. Bhagavathi S, Borromeo V, Desai H, Crisan D. Case report and literature review: a rare patient with chronic myeloid leukemia and chronic lymphocytic leukemia. Ann Clin Lab Sci. 2008;38(4):405-9.

12. Elm'hadi C, Khmamouche MR, Tanz R, Toreis M, Mahtat E, Allaoui M, Oukabli M, Messaoudi N, Errihani H, Ichou M. Successful management of synchronous recurrent breast carcinoma with chronic myelogenous leukemia: a case report. Journal of Medical Case Reports. 201701 10;11(1). https://doi.org/10.1186/s13256-016-1180-4

13. Pan L, Duan J, Qiao W, Bi L, Wu D, Fan Z, Yang M. Secondary breast carcinoma after completely remitted chronic myeloid leukemia following targeted tyrosine kinase inhibitor therapy. Breast Cancer. 201706 05;24(6):790-793. https://doi.org/10.1007/s12282-017-0786-8

14. Campione E, Diluvio L, Paternò EJ, Di Marcantonio D, Francesconi A, Terrinoni A, Orlandi A, Chimenti S. Kaposi's sarcoma in a patient treated with imatinib mesylate for chronic myeloid leukemia. Clinical Therapeutics. 2009 Nov;31(11):2565-2569. https://doi.org/10.1016/j. clinthera.2009.11.018

15. Chotel F, Franck F, Solla F, Dijoud F, Kohler R, Berard J, Abelin Genevois K. Osteoid osteoma transformation into osteoblastoma: Fact or fiction?. Orthopaedics \& Traumatology: Surgery \& Research. 2012 Oct;98(6):S98-S104. https://doi. org/10.1016/j.otsr.2012.03.017

16. Gamba J, Martinez S, Apple J, Harrelson J, Nunley J. Computed tomography of axial skeletal osteoid osteomas. American Journal of Roentgenology. 1984 04;142(4):769772. https://doi.org/10.2214/ajr.142.4.769

17. Juncá Piera J, Durán Suárez J, Triginer Boixeda J. [Osteolytic lesions in chronic myeloid leukemia. Report of three cases (author's transl)]. Med Clin (Barc). 1981 Mar 25;76(6):25961.

18. Nesbitt J, Roth RE. Solitary Lytic Bone Lesion in an Adult with Chronic Myelogenous Leukemia. Radiology. 1955 05;64(5):724-726. https://doi.org/10.1148/64.5.724

19. Rizzo S, Fontana G, Ricevuti G, Balduini C. Osteolytic lesions in chronic granulocytic leukemia: a report of four cases. Haematologica. 1977;62(1):61-74.

20. Chronic Myeloid Leukemia with Osteolytic Bone Involvement [Internet]. [cited 2021 May 26]. Available from: https://www.japi.org/v2e4b464/chronic-myeloid-leukemiawith-osteolytic-bone-involvement.

21. Shin Y, Kim J. Intracortical Bone Metastasis Mimicking Intracortical Osteoid Osteoma: A Case Report. undefined [Internet]. 2007 [cited 2021 May 26]; Available from: / paper/Intracortical-Bone-Metastasis-Mimicking-Osteoid-AShin-Kim/f322e1ae0dcd531f2ef5327d9b5b8490857c413c.

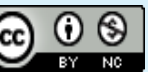

This work is licensed under a Creative Commons AttributionNon Commercial 4.0 International License. 